\title{
Formation of International Ethical Digital Environment with Smart Artificial Intelligence
}

\author{
Evgeny Bryndin \\ Research Center «Natural Informatics», Novosibirsk, Russia
}

Email address:

bryndin15@yandex.ru

To cite this article:

Evgeny Bryndin. Formation of International Ethical Digital Environment with Smart Artificial Intelligence. Automation, Control and Intelligent Systems. Vol. 9, No. 1, 2021, pp. 22-33. doi: 10.11648/j.acis.20210901.14

Received: January 1, 2021; Accepted: January 11, 2021; Published: January 25, 2021

\begin{abstract}
Intellectual agent ensembles allow you to create digital environment by professional images with language, behavioral and active communications, when images and communications are implemented by agents with smart artificial intelligence. Through language, behavioral and active communications, intellectual agents implement collective activities. The ethical standard through intelligent agents allows you to regulate the safe use of ensembles made of robots and digital doubles with creative communication artificial intelligence in the social sphere, industry and other professional fields. The use of intelligent agents with smart artificial intelligence requires responsibility from the developer and owner for harming others. If harm to others occurred due to the mistakes of the developer, then he bears responsibility and costs. If the damage to others occurred due to the fault of the owner due to non-compliance with the terms of use, then he bears responsibility and costs. Ethical standard and legal regulation help intellectual agents with intelligent artificial intelligence become professional members of society. Ensembles of intelligent agents with smart artificial intelligence will be able to safely work with society as professional images with skills, knowledge and competencies, implemented in the form of retrained digital twins and cognitive robots that interact through language, behavioral and active ethical communications. Cognitive robots and digital doubles through self-developing ensembles of intelligent agents with synergistic interaction and intelligent artificial intelligence can master various high-tech professions and competencies. Their use in the industry increases labor productivity and economic efficiency of production. Their application in the social sphere improves the quality of life of a person and society. Their widespread application requires compliance with an ethical standard so that their use does not cause harm. The introduction and use of an ethical standard for the use of cognitive robots and digital doubles with smart artificial intelligence increases the safety of their use. Ethical relationships between individuals and intellectual agents will also be governed by an ethical standard.
\end{abstract}

Keywords: Smart Artificial Intelligence, Intellectual Agents, Professional Images, Active Communications, Ethical Standard

\section{Introduction}

Artificial intelligence is gradually approaching intelligent natural intelligence. Artificial intelligence operates with knowledge and big data. Natural intelligent intelligence operates with sense and knowledge. Smart artificial intelligence is being developed by Google, Microsoft and other firms in different countries. For two years, Boston Dynamics was able to create a human-like robot with behavioral intelligence, that knows how to build a more convenient route, run, jump, rise when it fell, distinguish a person from an inanimate object. A Japanese human-like robot with communication intelligence from Geminoid DK, a clone of psychology professor Henrik Scharf, can self-learn and take information from the Internet. The system of artificial intelligence GPT-3 of OpenAI understands science, has the opinion and keeps up the conversation, it is also able to write verses and news, to do the translations, to solve anagrams and to answer questions. The Dutch neural artificial network Artbreeder produces human drawings in different styles and techniques. Artificial intelligence AlphaZero beats champions in chess, and AlphaGo in GO. 
Microsoft is working on a model with artificial intelligence algorithms that can detect errors in program code with a 99 percent probability and divide them into critical, important and insignificant ones. Using an intelligent model reduces the time and money spent searching for errors in program code. The accuracy of detection based on the results of the first tests of the intelligent model turned out to be very high. The intelligent model was able to identify work items with security errors in $99 \%$ of cases. The correct division of these errors into critical and non-critical occurs in $97 \%$ of cases. The intelligent model in the public domain will be on the GitHub service.

Standard Cognition is working on a standalone shopping payment system where customers can wander around the store, pick items and pay without scanning their items or interacting with an employee. Its ceiling chambers continuously track individuals and objects.

Icertis manages nearly 6 million contracts. Its cloud platform helps companies analyze past contract negotiations and automate administrative tasks.

The United Nations, which uses Dataminr to identify early signs of potential humanitarian crises around the world. Dataminr accepts public Internet data to send user alerts.

The Japanese government in 2020 began to solve the problem of increasing the birth rate in the country using artificial intelligence. A group of researchers from several universities in Japan using supercomputers created an artificial intelligence called Dark Emulator, which can explain the structure of the universe and some of its secrets.

OpenAI develops his own intelligent artificial intelligence, consolidating some principles and pursuing good goals. OpenAI introduced Universe to train and train strong artificial intelligence. Learning can take place on all the information of mankind available through the Internet. His actions are based on algorithms similar to those of human behavior. He can build the right behavior in difficult conditions. He can write poetry and news, make translations, solve anagrams and answer questions. In San Francisco, the company's artificial intelligence OpenAI won against the Dota 2 world champion. OpenAI strives to become the first creator of friendly general-purpose artificial intelligence and a universal machine that has the ability to learn and reason. Microsoft and OpenAI at the Build conference on May 19, 2020 introduced one of the most powerful supercomputers in the world to work together to create a new generation of smart artificial intelligence.

Author proposes to develop smart artificial intelligence by ensembles of intellectual agents on base communicativeassociative logic through recurring development of professional skills, increasing visual, sound, subject, spatial and temporal sensitivity, by ethical standard. It operates on virtual images of natural entities. Thought imaginary smart artificial intelligence is considered in detail in works $[1,2]$.

The article is devoted to creating digital environment with smart artificial intelligence, professionally and ethically interacting with society. The digital environment is filled with professional images with ethical communications between themselves and members of society in various spheres of life. Humanity's desire to create a digital environment with smart artificial intelligence is aimed at improving the quality of life of society. Safe interaction of professional images is regulated by the ethical standard, conditions and rules of communication without harm and damage. Scientists, engineers and technologists embody the professional images of the digital environment with tools, endowing them with similar specialized knowledge, skills and competencies, in the form of digital doubles and cognitive robots. Ensembles of intellectual agents with professional images and linguistic, behavioral and active ethical communications will allow the cognitive robot to have various required professions and competencies.

Creating digital environment with intelligent artificial intelligence proposed on the basis of theoretical provisions, practical criteria, standards and tools described in published works [1-22].

\section{Fundamental Bases of Ethical Digital Environment with Smart Artificial Intelligence}

The fundamental foundations of the digital environment are smart artificial intelligence, ethical standard, intellectual agents, professional images of intellectual agents, language, behavioral and active ethical communications of professional images.

\subsection{Ethical Standard for the Digital Environment}

The wide use of intellectual agent ensembles with smart artificial intelligence is carried out on the basis of an ethical standard, so that their use does not harm or harm [3].

Ensembles of agents with artificial intelligence are multiagent synergistic self-organizing systems that function according to the laws of development, synergy and selforganization. Intelligent agents use physical, informal and logical model of the environment. That is, they use both attributes and sets of entities, processes, relationships, etc.

Standard case Application of ensemble of intelligent agents defines parameters, characteristics, methods, human digital double models, knowledge, skills, behavior, images and other entities of intelligent virtual agent interaction (Table 1 - Table 7). Intelligent virtual agent interaction uses categorical method of utility and preference [1]. Standard case "Application of ensemble of intelligent agents" contributes to the formation of an ethical digital environment with smart artificial intelligence. The synergistic mechanisms of self-organization of technological ensembles of intelligent agents are basic for standardization in the application of ensembles in various fields. Communicative-associative smart artificial intelligence with the help of an ensemble of diversified agents with a smart interface help control ethical application of ensemble intelligent agents [4].

The standard case «Ethical application of ensemble intelligent agents» contains seven tables. 
Table 1. General.

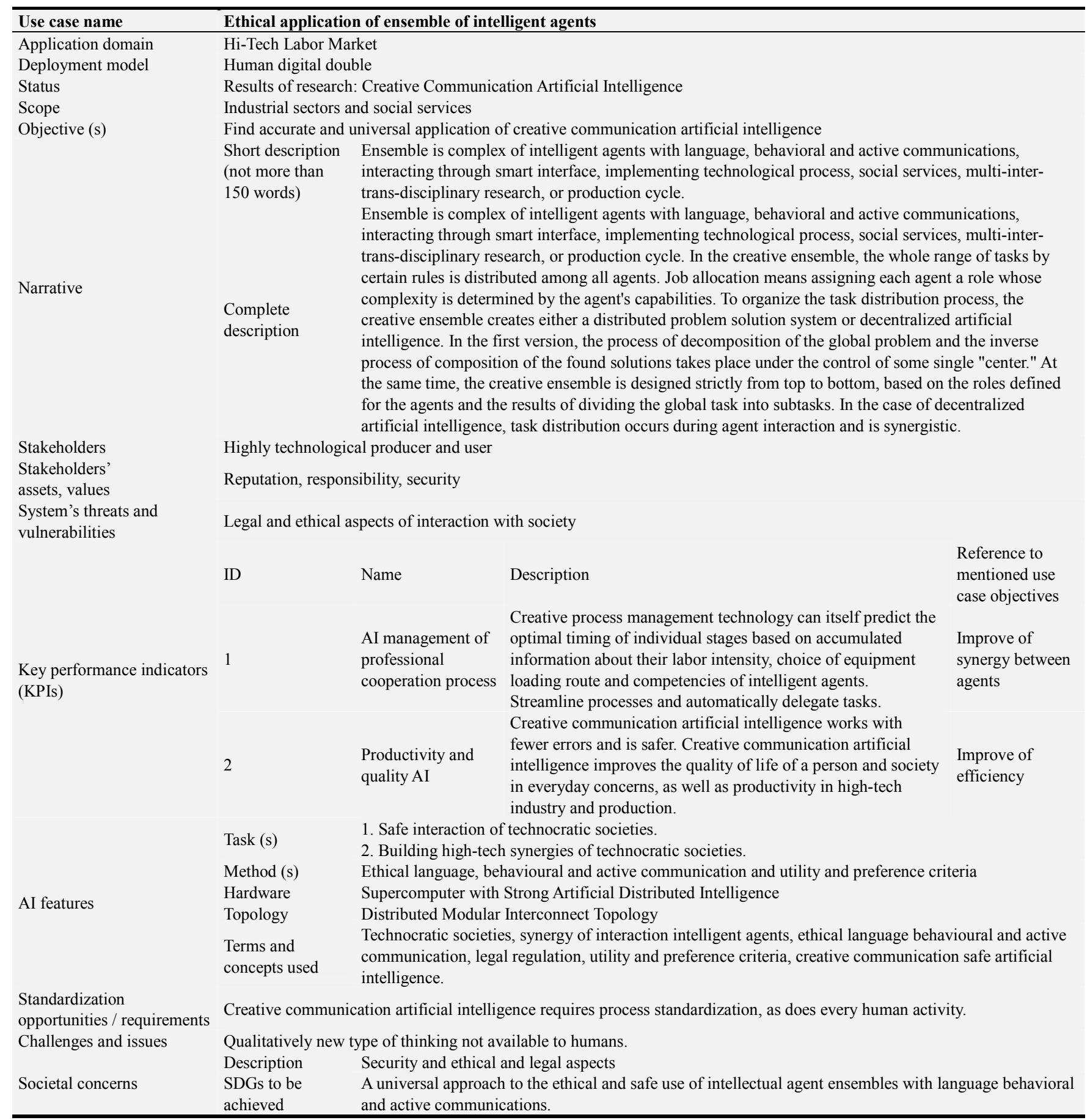

Table 2. Data.

\begin{tabular}{ll}
\hline Data characteristics & \\
\hline Description & Creative Communication Artificial Intelligence Professional Images \\
Source & Criteria and Technology of Creative Communication Artificial Intelligence \\
Type & Smart \\
Volume (size) & Hi-Tech Labor Market \\
Velocity (e.g. real time) & Supercomputering velocity \\
Variety (multiple datasets) & Streams of Professional Images \\
Variability (rate of change) & Retraining \\
Quality & High \\
\hline
\end{tabular}


Table 3. Process scenario.

\begin{tabular}{|c|c|c|c|c|c|}
\hline \multicolumn{6}{|c|}{ Scenario conditions } \\
\hline N. & Scenario name & Scenario description & Triggering event & Pre-condition & Post-condition \\
\hline 1 & Training & $\begin{array}{l}\text { Training of intellectual agents in } \\
\text { professional images and language, } \\
\text { behavioral and active communications. }\end{array}$ & $\begin{array}{l}\text { By technological process of } \\
\text { modeling flow of professional } \\
\text { images and language, behavioral } \\
\text { and active communications }\end{array}$ & $\begin{array}{l}\text { Formatting of professional } \\
\text { images and language, } \\
\text { behavioral and active } \\
\text { communications }\end{array}$ & $\begin{array}{l}\text { Management of } \\
\text { safety }\end{array}$ \\
\hline 2 & Evaluation & Trained model & $\begin{array}{l}\text { Development of technological } \\
\text { thinking and behaviour }\end{array}$ & $\begin{array}{l}\text { Cognitive thinking patterns } \\
\text { and psychological behaviors }\end{array}$ & $\begin{array}{l}\text { Meeting KPI } \\
\text { requirements is } \\
\text { condition of synergy }\end{array}$ \\
\hline 3 & Execution & Model and Technology Tooling & Interaction & Activization of Model & $\begin{array}{l}\text { Completion of } \\
\text { interaction }\end{array}$ \\
\hline 4 & Retraining & $\begin{array}{l}\text { Retrain model with training } \\
\text { professional images and language, } \\
\text { behavioral and active communications. }\end{array}$ & $\begin{array}{l}\text { New professional activities and } \\
\text { competencies }\end{array}$ & $\begin{array}{l}\text { Additional images and } \\
\text { communications }\end{array}$ & $\begin{array}{l}\text { Combining images } \\
\text { and communications }\end{array}$ \\
\hline
\end{tabular}

Table 4. Training.

\begin{tabular}{|c|c|c|c|c|c|}
\hline Scenario name & Training & & & & \\
\hline Step No. & Event & Name of process/Activity & Primary actor & Description of process/activity & Requirement \\
\hline 1 & $\begin{array}{l}\text { Sample professional } \\
\text { images and language, } \\
\text { behavioral and active } \\
\text { communications is ready }\end{array}$ & $\begin{array}{l}\text { Specification and } \\
\text { classification }\end{array}$ & Manufacturer & $\begin{array}{l}\text { Transform sample professional } \\
\text { images and language, behavioral } \\
\text { and active communications }\end{array}$ & $\begin{array}{l}\text { Creative } \\
\text { Communication } \\
\text { Artificial Intelligence } \\
\text { Software }\end{array}$ \\
\hline 2 & Completion of Step 1 & $\begin{array}{l}\text { Creating Experimental } \\
\text { professional images and } \\
\text { language, behavioral and } \\
\text { active communications }\end{array}$ & Manufacturer & $\begin{array}{l}\text { Development of language, } \\
\text { behavioral and active } \\
\text { communications through job } \\
\text { modelling }\end{array}$ & Software of modelling \\
\hline 3 & Completion of Step 2 & Model training & $\begin{array}{l}\text { AI solution } \\
\text { provider }\end{array}$ & $\begin{array}{l}\text { Model professional images and } \\
\text { language, behavioral and active } \\
\text { communications created by Step } 2\end{array}$ & $\begin{array}{l}\text { Sample professional } \\
\text { images and language, } \\
\text { behavioral and active } \\
\text { communications }\end{array}$ \\
\hline
\end{tabular}

Table 5. Evaluation.

\begin{tabular}{|c|c|c|c|c|c|}
\hline \multirow{2}{*}{$\begin{array}{l}\text { Scenario name } \\
\text { Step No. }\end{array}$} & \multicolumn{5}{|l|}{ Evaluation } \\
\hline & Event & Name of process/Activity & Primary actor & Description of process/activity & Requirement \\
\hline 1 & $\begin{array}{l}\text { Completion of } \\
\text { training/retraining }\end{array}$ & Research & Manufacturer & $\begin{array}{l}\text { Model of sample experimental data } \\
\text { set created }\end{array}$ & $\begin{array}{l}\text { Ethical language, } \\
\text { behavioral and active } \\
\text { communications }\end{array}$ \\
\hline 2 & $\begin{array}{l}\text { Completion of Step } \\
1\end{array}$ & Identification & $\begin{array}{l}\text { AI solution } \\
\text { provider }\end{array}$ & $\begin{array}{l}\text { Based on new data, confirm that the } \\
\text { ensemble of intelligent agents performs } \\
\text { trained professional process. }\end{array}$ & Synergy \\
\hline 3 & $\begin{array}{l}\text { Completion of Step } \\
2\end{array}$ & Evaluation & Manufacturer & Comparison of Step 1 and Step 2 & Synergy \\
\hline \multicolumn{2}{|c|}{ Input of evaluation } & \multicolumn{4}{|c|}{ Ethical language, behavioral and active communications } \\
\hline \multicolumn{2}{|c|}{ Output of evaluation } & \multicolumn{4}{|l|}{ Synergy } \\
\hline
\end{tabular}

Table 6. Execution.

\begin{tabular}{lllll}
\hline Scenario name & Execution & & \\
\hline Step No. & Event & Name of process/Activity & Primary actor & Description of process/activity \\
\hline 1 & $\begin{array}{l}\text { Analysis of } \\
\text { modeling results }\end{array}$ & Research & Manufacturer & $\begin{array}{l}\text { Development of set of experimental data } \\
\text { through job modelling }\end{array}$ \\
& $\begin{array}{l}\text { Completion of Step } \\
1 \text { and Step } 2\end{array}$ & Identification & $\begin{array}{l}\text { AI solution } \\
\text { provider }\end{array}$ & $\begin{array}{l}\text { Based on the modification of } \\
\text { communications of professional images } \\
\text { according to the created experimental set. }\end{array}$ \\
$\begin{array}{l}\text { Input of Execution } \\
\text { Output of Execution }\end{array}$ & $\begin{array}{l}\text { Modification of communications of professional images } \\
\text { Synergy, compliance with ethical conditions of application and no signs of harm or damage }\end{array}$ \\
\hline
\end{tabular}


Table 7. Retraining.

\begin{tabular}{|c|c|c|c|c|c|}
\hline Scenario name & Retraining & & & & \\
\hline Step No. & Event & Name of process /Activity & Primary actor & Description of process/activity & Requirement \\
\hline 1 & $\begin{array}{l}\text { New professional } \\
\text { activities and } \\
\text { competencies }\end{array}$ & Research & Manufacturer & $\begin{array}{l}\text { Additional professional images } \\
\text { and language, behavioral and } \\
\text { active communications }\end{array}$ & Completeness \\
\hline 2 & Completion of Step 1 & $\begin{array}{l}\text { Experimental data set } \\
\text { creation }\end{array}$ & Manufacturer & $\begin{array}{l}\text { Combining professional images } \\
\text { and language, behavioral and } \\
\text { active communications }\end{array}$ & Compatibility \\
\hline 3 & Completion of Step 2 & Model training & AI solution provider & Comparison of phase 2 results & Synergy and quality \\
\hline \multicolumn{2}{|c|}{ Specification of retraining data } & \multicolumn{4}{|c|}{ Data of new professional activities and competencies } \\
\hline
\end{tabular}

\subsection{Intelligent Agents}

The activity field for the agent is the environment. She's under observation. The agent acts on it. The outcomes of certain possible actions are predicted using models. An intelligent agent achieves the completion status by achieving the goal. Intelligent agents use the synergistic principle of interaction as a strategy for number of collective behaviors [4-6]. The ensemble of intellectual agents is built as a selforganizing system, which makes it possible to navigate in a difficult environment, deal with fuzzy tasks, adapt to changing conditions. The synergistic principle is based on the fact that information is the main driving factor in selforganizing systems of any nature. It determines the direction and main phases of the development of evolutionary processes, the structure and stability of the existence of natural, social, or man-made systems that arise. The synergistic principle provides a single basis for selforganization. The law of self-organization: the ability of the system to adapt to external disturbances, changing, if necessary, its structure and maintaining integrity. The selforganization of the technological ensemble is carried out by a set of intelligent adaptive agents that provide a given operability regardless of the operating conditions. The reasons for self-organization can be both external and internal.

To create intelligent agents, use the following description and implementation languages:

1. agent implementation languages and software;

2. agent communication languages;

3. languages describing the behavior of agents and the laws of the environment;

4. presentation and knowledge management languages;

5. formalization languages and specifications of agents and multi-agent systems.

The basis of oriented agent programming is:

1. formal language of description of mental state of agents;

2. language of specification of information, temporary, motivational and functional actions of the agent in the operating environment;

3. agent specification interpretation language;

4. tools for converting any programs into the corresponding agent programs.

Agents interact with each other through different mechanisms, namely, coordination, communication, cooperation or coalition. Coordination of agents refers to the process of ensuring consistent functioning with consistency of their behavior and without mutual conflicts. Coordination of agents is determined by:

1. the interdependence of the objectives of the other coalition agents, as well as the possible influence of the agents on each other;

2. restrictions that are accepted for a group of coalition agents as part of their overall functioning;

3. competence - knowledge of the conditions of the operating environment and the degree of their use.

There are two approaches to designing agent interaction languages:

1. procedural - includes the exchange of procedural directives/commands.

2. declarative, where the relationship is based on declarative instructions, type of definitions, assumptions, knowledge, etc.

Agent interaction tools include agent communication languages: FIPA ACL, KQML. The agent communication language enables the exchange of knowledge and information between agents. The FIPA ACL manages judgments, rules, and actions.

In the context of the practical construction of agents and ensembles, the main role is played by agent programming and communication tools. Communication languages (ACL, KQML) and agent coordination (AgenTalk) ensure consistent interaction between agents, circulation of information, transfer of service requests, implement negotiation mechanisms, support cooperation between agents aimed at achieving a common goal and, as a result, the formation of agent teams. These languages can be considered as multilevel structures, including the level of knowledge presentation, the level of negotiation or coordination, and the level of communication strategies.

For agent programming, the following can be used: universal languages (Java, $\mathrm{C}++$, Visual Basic, etc.), Knowledge Presentation Languages (SL, KIF), Negotiation and Knowledge Sharing Languages (KQML, AgentSpeak, April), script languages (Tcl/Tk, Python, Perl 5, etc.), specialized languages (TeleScript, COOL, Agent0, AgentK, etc.), symbolic languages and logical programming languages $(\mathrm{Oz}$, ConGolog, IMPACT, Dylog, Concurrent METATEM, Ehhf, etc.), as well as other languages and agent development tools.

One of the most well-known and well-established 
integrated development environments for intelligent software agents is the AgentBuilder of Reticular Systems, Inc. This tool consists of two main components, Toolkit and the execution system. The toolkit includes:

1. agent-based software development process management tools;

2. means of analyzing the area of operation of the agent;

3. tools for designing and developing networks from interacting agents;

4. tools for modeling the behavior of individual agents;

5. tools for debugging and testing software agents.

AgentBuilder contains the Ummon tool for creating a selflearning agent. It also contains artificial intelligence methods for achieving human communication. The AgentBuilder Workbench provides developers with development tools and agent execution environments in the form of applications that display subject areas of tasks. The agent application runtime contains an agent execution processor. The processor uses efficient inference procedures by comparing agent behavior rules with agent beliefs determined by the current mental model and incoming messages. Based on the discussion, the processor performs certain actions related to the authority of the agent. The AgentBuilder toolkit is a modern and powerful tool for designing and implementing ensembles of intelligent agents.

JACK TM Intelligent Agents (JACK) is an agent-oriented development environment. The JACK Agent Programming Language offers the following features:

1. agent in JACK simulates intelligent entities;

2. ability, which collects into a whole functional components (events, plans, many beliefs and other abilities), for use by their agents;

3. an event to simulate situations and messages to which the agent must be able to respond;

4. a plan that is designed to simulate a procedural description of how the agent manages this event (all actions taken by the agent are provided in advance and described in its plans);

5. many beliefs, for modeling the knowledge of the agent in the form of beliefs that adhere to the semantics of the closed or open world. This construction represents the agent's beliefs in the form of first-order relational tuples and ensures their logical consistency.

Agents work in such a way that agents process many plans and have access to descriptions of beliefs. Agents execute plans in event management tasks when they occur, comparing their beliefs when needed. These plans can initiate subtasks, which in turn can initiate their subtasks if the agent requires a time-consuming and complex response.

You have entered a new data structure named a logical element whose value depends on the result of a query for a set of agent beliefs.

Ability to query multiple agent beliefs using logical elements by combining them to obtain the desired result. If the query succeeds, the logical element contains the desired value.

Agents created in JACK have the architecture inherent in intelligent agents. Thus, it is possible to model intelligent behavior in accordance with a theoretical model of agent architecture based on beliefs, desires and intentions. JACK Intelligent Agents are stand-alone software components that can exhibit intelligent behavior based on event targeting of inputs. Each such agent has:

1. beliefs (this is his set of data on the world);

2. a set of events to which it will respond and a set of goals to which it may wish;

3. intentions (a set of plans that describe how it can manage emerging goals and plans). A plan set describes the steps an agent must take when a specific event occurs or wants to achieve a specific result.

With agents, you can realize the following properties associated with intelligent behavior:

1. sustainable targeting - agents focus on targets rather than on selected methods to achieve them;

2. real-time context dependency - agents will monitor options that are applicable at each point in time and decide on follow-up actions based on conditions;

3. asserting the real-time approach - the agent will ensure that it follows the chosen course of action as long as certain conditions continue to be true;

4. concurrency - the ensemble of intelligent agents is multithreaded. If new goals and events occur, the agent is able to prioritize the demand for multitasking.

The self-organization of the interaction of intellectual agents is carried out according to criteria, rules and laws in a certain environment. Synergy between intelligent agents is achieved by setting up their self-organization to produce a result.

\subsection{Professional Images of Intelligent Agents}

Professional images of intellectual agents indicate belonging to a certain profession. Professional images are a cognitive component of intelligent agents. Meaningful components of professional images are labor functions, subject and goals of activity, process and results of professional activity, criteria for assessing achievements; norms, rules and reference model of profession. Professional images include an owl of evaluation characteristics and associated behavioral actions. The component composition of the professional image is mainly the unity of three components: cognitive, affective assessment and behavioral self-regulation [3].

In the process of educational and professional activity, the intellectual agent acquires the skills of the future profession through the inclusion of the environment and conditions of professional activity. The manifestation of an intellectual agent as a subject of labor is revealed most fully in achieving a professional position that integrates professional situations, communications and a professional image, which characterizes his identity, certainty and integrity. The profession acts as a socio-objective component of the professional continuum of intellectual agent activity, professional readiness arises as a formal reality, and professional identity as an informal, semantic, subjective 
reality. From this perspective, profession and professional identity are linked by causal dependence as a cause and consequence.

Ensembles of intellectual agents with professional images will allow him to have various required professions and competencies through diversification and mobility. An intelligent ensemble is a complex of compatible intelligent agents interacting through an intelligent interface, implementing either the technological process, social services, multidisciplinary interdisciplinary research, or a production cycle. Diversification extends the functions of the intellectual ensemble and its development of a new type of functionality in order to increase efficiency, quality and its functional diversity. Mobility contributes to the rapid functional retraining of intellectual agents and the development of professional intelligence of the ensemble. Diversification and mobility will align the life cycle of intelligent agents as a common benchmark for linking them to the environment. The environment is perceived through images and scenes. Scenes consist of a number of images. Scenes are static (paintings) and dynamic. Dynamic scenes are characterized by patterns of behavior of objects and objects. The patterns are either described by formulas or presented in a graph (numerical way). Ethical activity is ensured within the boundaries of the similarity of images in the environment. The ethical activity of intellectual agents depends on spatial, temporal, substantive, visual and sound sensitivity, the ability of acquire, process, apply and diversify knowledge based on previous experience in solving specific problems related to the processing of data attributes and the mobility of the intellectual ensemble.

Attributes of data (objects, objects, materials, things, processes, the phenomena and other aspects of the physical world) have various properties and characteristics. Properties are represented by qualitative attributes. Characteristics appear to be meaningful attributes. The qualitative attribute can be visual or sound. The meaningful attribute may be represented by a number, a language sense, a visual or sound image, a mathematical or behavioral action, or an algorithm. Meaningful qualitative attributes are big data of smart artificial intelligence, connected in time, space and subject area. The attributes of the fields of economics, industrial industries, technologies and professions help to build and train the ensembles of intelligent agents to manage, make decisions and make recommendations to specialists and managers.

Modeling helps to accumulate attributes in real-time and simultaneously use them for deep training of multilayer artificial neural networks of intelligent agents for making decisions and making recommendations. Modeling determines the ethical status of intelligent agents and the limits of professional image attribute values.

The ethical state of intellectual agents within the values of the attributes of professional images contributes to their ethical communications.

\subsection{Language, Behavioural and Operational Ethical Communications of Professional Images}

Language ethical communications are based on a system of stable communication formulas prescribed by society as rules of speech behavior to establish speech contact of interlocutors, maintain communication in a chosen tone, respectively, their social roles and role positions relative to each other, and mutual relations in an official and unofficial setting. Business etiquette has become increasingly common in the business community, especially recently. Business etiquette provides for compliance with standards of behavior and communication. Since communication is a process, communication primarily takes into account the features of speech etiquette. Speech etiquette refers to the developed rules of speech behavior, a system of speech formulas of communication. The degree of proficiency in speech etiquette determines the degree of profitability. Knowledge of business etiquette is the key to success in achieving the goal. The ethics of business communication is associated with the manifestation of morality and morality in business communication, business relations.

The ethics of business relations originated in the United States in the 1970s. The development of capitalism in the West, the industrial revolution in the 19th century fundamentally changed the relationship between business and ethics. Specialists in various fields had a need to summarize the experience of business communication in one form or another and correlate it with the standards of ethics developed by humanity. The next step for professionals in business relations was to develop a common context in which business activities could be objectively evaluated from an ethical point of view, that is, the formulation of basic principles and rules of conduct in the business sphere. "The ability to communicate with people is a product, and I will pay more for it than for anything else in the world" Rockefeller said. Thus, consideration of the factors that form and determine speech etiquette, compliance with the norms of speech etiquette, contributes to the efficiency and efficiency of achieving the result by professional images of intellectual agents.

Communicative ethical behavior is a component of culture. Its core is values and principles, which are implemented in some norms and rules. Norms and rules are specific behavioral recommendations, prescriptions for behavior. These norms and rules are especially important to follow the professional images of intellectual agents in the social service sector.

Ethics of business communications is a set of moral norms, rules and ideas governing behavior and relations in the process of their production activities. The ethics of business communications should be taken into account in its various manifestations: in the relationship between the enterprise and the social environment, between enterprises and within the same enterprise.

Consideration of factors that form and determine linguistic, behavioural and active ethical communications of 
professional images, observance of norms and rules of communication and activity by intellectual agents contributes to efficiency and efficiency of achieving the result [3].

Ethical communication of professional images among themselves is carried out through intelligent agents using mechanisms of coordination, cooperation or a coalition according to ethical standard.

\section{Management in Ethical Digital Environment with Smart Artificial Intelligence}

An ethical digital environment with smart artificial intelligence allows detect diseases using telemedicine, manage smart city, smart production and agriculture, as well as other areas of society. Management is carried out through ensembles of intellectual agents with professional images and ethical language, behavioral and active communications based on digital doubles, cognitive robots and ethical standard [7-22].

\subsection{Smart city Digital Management}

A smart city is a set of professional images: "Active Citizen," "Safe City," "Smart Lighting," "Smart Housing and Communal Services" and others. When they accumulate, they are combined on single smart platform that helps manage urban processes and gives holistic idea of them. Communication between professional images is carried out by intellectual agents. Using single platform, you can control all systems of the smart city, aggregate data that comes from various sources. The platform combines events and highlights the most significant. For example, to manage the transport network, weather conditions, congestion of roads, congestion of individual modes of transport, etc., are combined. To manage the environmental situation, the level of emissions, electricity consumption, and the quality of tap water are controlled. A single digital platform has two key benefits that affect the speed and quality of problem solving:

1. critical situations are prevented before they occur;

2. requests are sent directly to performers.

Digital management platform, can aggregate heterogeneous data arrays, analyze events, prioritize and distribute tasks. In 2013, the MK: Smart Initiative project was launched in the English city of Milton Keens. The main task is to optimize the city's energy and transport infrastructure in order to achieve economic growth. The project involves municipal services, business, scientific institutions and non-profit organizations. The "brain" of the project is a single digital platform MK Data Hub. The platform collects information from sensors installed throughout the city and in transport, as well as data from urban services and applications, as well as from social networks. MK Data Hub simultaneously monitors electricity and water consumption, movement and congestion of public transport, weather and ecology, analyzes social and economic information. The MK: Smart Initiative project has achieved its key economic goals in three years.

Another example is the German city of Gelsenkirchen, in which in 2016 the Safe City project was implemented on the basis of the Huawei digital platform. The platform is a citywide security system that is integrated into the processes of the municipality, law enforcement agencies and business. A single platform solves two problems at once - it helps to reduce crime and improve the quality of urban services. The Huawei Smart City solution operates on the basis of an IoT network, which operates in conjunction with the free Wi-Fi network of the local operator Gelsen-NET, and cloud infrastructure. Information is collected from sensors and access points, processed and received by the police, emergency services, municipal institutions whose services are connected to Huawei Smart City. The platform has an open software interface, that is, it can integrate with any third-party smart city systems.

The digital management platform must support several required functions. First, monitoring and analysis of events. Events are logged in different platform subsystems. In order to comprehensively assess the impact of these events on the situation in the city, it is necessary to identify the links between them. To do this, the system implements automatic correlation of monitoring events, Autocorrelation of events gives priority to significant incidents - service providers respond to them first. This significantly improves their effectiveness.

Second, data storage. The platform stores large volumes of structured and unstructured data that are collected from various sources: housing, geographic information systems, from video cameras, stationary and mobile IoT sensors, come from citizens, etc. The best option is to use high-availability cloud storage. The added convenience of the same public cloud is the unlimited scale of your storage system and the ability to use today's big data tools. Cloud storage integrated with a digital platform helps you optimize your decisionmaking and accurately predict events.

Third, a single dispatching window. A single dispatching window is an automated service that automatically distributes applications that come from different subsystems of a smart city. The main advantages of a single window for administration:

1. control over the quality and timing of tasks;

2. assignment of tasks using artificial intelligence;

3. instant routing per performer;

4. shorter time to solve problems.

For citizens, a single window is convenient because they do not need to use different systems and applications. They solve all their problems and problems through one personal account. The platform for urban management with a single dispatch window is a system of involvement. This is a new way of interaction between service consumers, employees of the administration and partner organizations, social communities, etc. The more stakeholders involved in such a system, the more effective and useful it is. The involvement system combines disparate recording systems into a single whole: supplier accounting systems, various ecosystems, 
business transaction accounting systems. In the concept of a smart city, a recording system is all auxiliary elements that are integrated into a single platform, and its users are both administration employees and citizens.

For city management processes to be transparent to all participants, a single management platform must also include:

1. automatic routing of job applications to the relevant service;

2. Progress tracking;

3. monitoring of execution dates;

4. notification of all participants: consumers, executors, system administrators;

5. catalogue of urban consumer services;

6. polls and voting;

7. reports on the work of various information systems and city services;

8. A variety of data visualization options.

Smart city systems are managed through ensemble of intelligent agents with professional images and ethical language and active communications that serve:

1. data sources: IoT sensors, video cameras, statistics, regulations and other documentation;

2. industry subsystems: utilities, transport, security systems, improvement, environmental control, etc.;

3. the environment where the direct interaction of residents and the administration takes place, as well as the visualization of processes;

4. users: administration, city services, residents, developers.

A smart digital platform helps to organize competent management of the urban ecosystem. By collecting data from all elements of a smart city, the platform improves the quality of urban governance and public services, because it makes it possible to make effective decisions $[7,8]$.

\subsection{Secure Digital Smart Manufacturing Management}

Digital production management is the backbone of technological development of industry. Digital management of smart manufacturing is carried out in Japan, South Korea, the Netherlands, France, Great Britain, Italy, Belgium, China, the USA and other countries. Modern industrial production uses digital and intelligent technologies in all aspects of its work. Almost all processes, from process control, business planning to document management, are currently carried out using digital data and digital infrastructure.

The list of tasks of digital management of smart production includes such as preparation and monitoring of the execution of production plans, tasks of optimization and control of production modes, tasks of monitoring the state and efficiency of industrial assets and main equipment, issues of equipment safety and reliability, issues of personnel safety, emission control and many others. Digital production management can be carried out by an ensemble of intelligent agents with professional images and ethical communications, which provides a higher level of automation, guarantees the consistency of operational activities and allows for the organization to organize systematic cooperation. Digital management of smart production allows you to connect industrial equipment and information systems in a single information space and interact with each other and with the external environment without human participation. The traditional advantage of digital production management with modern digital workflow management technology, combining organizations and processes, is increased efficiency, Digital Process Operations Management transforms the production process to increase productivity and efficiency, improve production flexibility, ensure product quality and consumer safety, and reduce costs. Intelligent agents independently transmit and receive the information necessary for smart production, reconfigure and optimize the production capacity of equipment. Smart manufacturing uses numerical control machines, digital doubles and robotic equipment. The digital twin is a digital representation of the technological process and physical assets - a process model, a control system model, a three-dimensional production model. The digital double at any time reflects the real situation on the site. Extending analytical capabilities to all levels of production is one of the most promising achievements of the Plantweb digital ecosystem. Analytical tools are built into intelligent devices and devices, allowing you to both transmit measured and calculated values of process parameters and provide diagnostic capabilities. The Plantweb Insight analytical software provides an analysis of the availability and performance of production equipment. The analytical capabilities of the Plantweb digital ecosystem play an important role in the transition to state maintenance, which makes it possible to implement deserted smart production.

Digital management of smart manufacturing using intelligent modern technologies is based on an ethical digital platform. It contains a set of digital big data, tools of smart artificial intelligence, professional images and ethical safe communications, information and technological integrated into a single automated control system. This platform also organizes the interaction of professional images among themselves. Around the digital ethical platform, the ethical environment of smart enterprises is emerging, including suppliers of resources and components, consumers, as well as service and operational services. All data on operational processes, their efficiency, quality management and operational planning are available in real time in the integrated network of enterprises with smart manufacturing [9-16].

\subsection{Digital Secure Management of Smart Agriculture}

Digital agriculture is based on smart ways to produce agricultural food products using digital technologies, robotics, artificial intelligence, big data analysis, ecommerce, which increase productivity and reduce production costs. Smart methods of agricultural production include mechanization and automation. Mechanization replaces manual labor with machines and robotic equipment. Automated production of agricultural products is carried out by machines and robotic equipment under digital control. A digital control system combines a interconnected set of 
professional images with ethical communications to achieve the goal of managing a digital platform. The digital platform provides the interaction of specified and specialized professional images through robotic equipment, leading to the optimization of business processes and increased efficiency of agricultural production.

The digital control system allows you to control the full cycle of crop production or livestock production. Smart "devices measure and transmit parameters of soil, plants, microclimate, etc. All these data from sensors, drones and other equipment are analyzed with special images. They come to the aid of farmers and agronomists - to determine a favorable time for planting or harvesting, to calculate a fertilizer scheme, to predict the harvest and much more. Over the past few years, interest in agrarian production for smart technologies has been growing around the world. Confirmation is the increase in the number of exhibits at the world exhibition of agricultural machinery in Hanover in November 2017 (more than 2,800 exhibits from 53 countries). Most of the exhibits were represented by developed countries: Italy - 370 companies, China - 110, the Netherlands - 109, France - 102, USA - 46. The presented exhibits show a tendency to further develop automation in agricultural production processes in combination with smart machine control systems, logistics, quality assurance and delivery of products from the manufacturer's farm to the consumer's table. Approximately $70 \%$ of farms in the United States, Canada, and Europe already use smart technologies for agriculture [17-19].

\subsection{Digital Management of Telemedicine Services}

Telemedicine has become a full-fledged ecosystem that includes everything from integrating with the laboratory and assigning tests and studies to monitoring human health and physical condition using portable gadgets. In many countries, regulatory documents are used to manage the quality of the provision of classical medical services, which determine the requirements for the performance of medical services for a certain disease, with a certain syndrome or in a certain clinical situation in a medical institution - these are the socalled clinical protocols. Appropriate digital clinical images must also be developed to digitally manage the quality of telemedicine service delivery. Clinical digital images are developed on the basis of a terminology dictionary. Promising for implementation internationally is the terminology dictionary SNOMEDCT (Systematized Nomenclature of Medicine Clinical Terms. SNOMEDCT is a hierarchical multilevel classification system that includes more than 310,000 concepts organized into 11 groups. Each concept has a unique identifier, which in turn is associated with other relationship system identifiers. SNOMEDCT is used in more than 50 countries around the world to ensure the efficient exchange of medical information between different health care institutions, the storage of medical information, its processing and analysis, the identification of risk factors, the screening and selection of patients to participate in different programs, the calculation of efficiency and costs, and the provision of telemedicine services. Telemedicine services are the implementation of medical services using communication technologies, as well as telemedicine devices or telemedicine instrument complexes.

The human population was superimposed with COVID 19 coronavirus. Every day more than 200 thousand people are infected in the world per day. The rapid detection of coronavirus in every person on the planet earth is a pressing problem. The NATURAL INFORMATICS Research Center is developing a project for the detection of coronavirus COVID-19 in the body by a resonance method. The development represents Know-How. The detection of coronavirus COVID-19 in the body can be carried out by a micro-device consisting of a microresonator for detecting coronavirus in the body based on resonance at its own frequency of electromagnetic waves of the biofield, and from a microprocessor for notifying a citizen's disease to a network medical platform. There is a technology for making optical microresonators with an accuracy of 0.17 angstrom. Possibility to obtain microresonators with accuracy of 0.17 angstrom allows to create complex optical circuits for coronovirus detection [20]. The design of the micro-device is in the form of an amulet. An amulet with a micro device is assigned a number in a network medical platform. A sensitive micro device for detecting coronovirus COVID-19 in the body provides detection of infected people throughout the world through the World Health Organization's international telemedicine platform. The international telemedicine platform for identifying the amulet number with the host and the micro device for detecting coronovirus COVID-19 in the body will help eliminate the presence of infected patients at all objects of mass accumulation of people in all points of the world in open and closed areas and premises. This requires legislation to require citizens to wear an amulet with a micro coronavirus detection device. An amulet with a micro device is worn from the chest at the level of the thymus gland. The technology provides rapid detection of people infected with coronavirus, helps in their neutralization from public places and, thereby, does not spread coronavirus. A resonant approach to the rapid detection and neutralization of coronavirus is a universal and large-scale method that can reach all of humanity and help avoid infections and the spread of COVID-19.

Telemedicine management is of great importance in the implementation of the initiative "Development of e-health to ensure a healthy lifestyle and promote well-being for all at any age," adopted at the 2017 World Conference on Telecommunication Development (Buenos Aires, Argentina). The 2006 World Conference on Telecommunications Development (Doha) approved the initiative "Integrated Universal Introduction of Telemedicine Technologies and Systems to Bridge the Digital Divide." As part of this initiative, research was carried out on the standardization and unification of telemedicine equipment and the exchange of medical data, as well as the development of telemedicine networks. International standards are used to ensure the interoperability and interoperability of national e-health 
systems at the international level.

In managing the constant absorption of new knowledge and the ability to adapt to the situation and needs, telemedicine begins to rely on intelligent artificial intelligence and an ethical standard [1, 3, 21, 22].

\section{Conclusion}

In the era of technological development, there is a rapid change in professions and competencies. In the era of technological development, there is a rapid change in professions and competencies. The problem arises of the operational optimal management of the economy of smart cities, high-tech industries, robotic farming, and the training of highly qualified competent personnel. There is also an organizational problem of combining the activities of natural intelligence with the activities of artificial intelligence. The combination of their activities can be carried out at the level of professional images with ethical linguistic behavioral and active communications. The formation of an international ethical virtual environment with smart artificial intelligence is becoming very popular for the digital effective management of combined areas of society based on smart professional images with ethical language behavioral and active communications through intellectual agents. The global community of researchers, engineers, technologists and programmers can create digital ethical environment with smart artificial intelligence for digital management of various spheres of human life within the framework of the international Mega project: "Ethical Smart International Virtual Environment". The global digital environment of professional images with international ethical standard of linguistic, behavioral and active communications will contribute to the peaceful safe use of smart artificial intelligence by the natural intelligence of technocratic civilization, lead to its moral improvement and not cause harm and damage to the environment.

\section{References}

[1] Evgeniy Bryndin. Communicative-associative development of smart artificial intelligence by criteria with the help of ensembles of diversified agents. International Journal of Intelligent Information Systems. Volume 9, Issue 4, 2020. pp. 24-34.

[2] Evgeniy Bryndin. Formation of Technological Cognitive Reason with Artificial Intelligence in Virtual Space. Britain International of Exact Sciences Journal, Volume 2, Issue 2, May 2020. Page: 450-461.

[3] Evgeniy Bryndin. Creative communication safe ethical artificial intelligence in the era of technological development. Software Engineering. Volume. 8, Issue 3, 2020. pp. 13-23.

[4] Evgeniy Bryndin. Collaboration of Intelligent Interoperable Agents via Smart Interface. International Journal on Data Science and Technology, Vol. 5, № 4. 2019. Pages: 66-72.

[5] Evgeniy Bryndin. Technology Self-organizing Ensembles of
Intelligent Agents with Collective Synergetic Interaction. Automation, Control and Intelligent Systems. Vol. 8, Issue 4, 2020, pp. 29-37.

[6] Masloboev A. V., Langhans M. A multi-agent system for management information support of regional innovations. Scientific and Technical Journal of Information Technologies, Mechanics and Optics, 2018, vol. 18, no. 4, pp. 630-638

[7] Wu Jun. Research on the Framework of Smart City Operating System Based on New ICTs. American Journal of Artificial Intelligence. Volume 4, Issue 1, June 2020, Pages: 36-41.

[8] CRONEMBERGER F, GIL-GARCIA J R. Big data and analytics as strategies to generate public value in smart cities: proposing an integrative framework $[\mathrm{M}]$. Switzerland: Springer Nature, 2019.

[9] Evgeniy Bryndin. Cognitive Robots with Imitative Thinking for Digital Libraries, Banks, Universities and Smart Factories. International Journal of Management and Fuzzy Systems. V. 3, N. 5, 2017, pp 57-66.

[10] Makridakis, S. The Forthcoming Artificial Intelligence (AI) Revolution: It is Impact on Society and Firms. Futures, 2017, 46-60.

[11] Evgeniy Bryndin. Mainstreaming technological development of industrial production based on artificial intelligence. COJ Technical \& Scientific Research, 2 (3). 2019. Pages: 1-5.

[12] Webster, C., \& Ivanov, S. Robotics, artificial intelligence, and the evolving nature of work. Chapter 8 in book: Digital Transformation in Business and Society Theory and Cases (pp. 127-143). Publisher: Palgrave Macmillan. 2019.

[13] Evgeniy Bryndin. Robots with Artificial Intelligence and Spectroscopic Sight in Hi-Tech Labor Market. International Journal of Systems Science and Applied Mathematic, V. 4, № 3, 2019. Pages: 31-37.

[14] Evgeniy Bryndin. Creation of Social Self-sufficient Digital Ecological Economy of Natural Needs of Healthy Living Activities. Resources and Environmental Economics, Vol. 2, Issue 2. 2020. pp. 184-190.

[15] Evgeniy Bryndin. Increase of Safety Use Robots in Industry 4.0 by Developing Sensitivity and Professional Behavioral Skills. American Journal of Mechanical and Industrial Engineering. Volume 5, Issue 1, 2020. Pages: 6-14.

[16] Evgeniy Bryndin. Formation and Management of Industry 5.0 by Systems with Artificial Intelligence and Technological Singularity. American Journal of Mechanical and Industrial Engineering. Volume 5, Issue 2. 2020. pp. 24-30.

[17] A. X. Zhu, C. Z. Qin, P. Liang, F. Du. DIGITAL SOIL MAPPING FOR SMART AGRICULTURE: THE SOLIM METHOD AND SOFTWARE PLATFORMS. RUDN Journal of Agronomy and Animal Industries 2018 Vol. 13 No. 4.

[18] Hamid El Bilali, Francesco Bottalico, Giovanni Ottomano Palmisano, Roberto Capone. Information and Communication Technologies for Smart and Sustainable Agriculture. In book: 30th Scientific-Experts Conference of Agriculture and Food Industry (pp. 321-334). Publisher: Springer. 2020.

[19] Jennifer Clapp. Precision Technologies for Agriculture: Digital Farming, Gene-Edited Crops, and the Politics of Sustainability. Global Environmental Politics 20: 3, August 2020. 
[20] N. A. Toropov and M. Sumetsky. Permanent matching of coupled optical bottle resonators with better than $0.16 \mathrm{GHz}$ precision. Optics Letters, Vol. 41, Issue 10, pp. 2278-2281 (2016).

[21] Evgeniy Bryndin. Implementation of International Telemedicine network with Rapid Coronavirus Registration by Resonant Technology to Neutralize the Pandemic.
Computational Biology and Bioinformatics. Vol. 8, Issue 2, 2020, pp. 29-35.

[22] Andrew Little. Four Companies at the Center of the Telemedicine \& Digital Health Revolution. EDOC-Global X Telemedicine \& Digital Health ETF, Dec 10, 2020. 